Chapter 20

An Approach to Develop Hansel-Spittel

Constitutive Equation during Ingot

Breakdown Operation of Low Alloy Steels

K. Chadha, D. Shahriari and M. Jahazi

- DOI: 10.1007/978-981-10-4819-7_20 


\title{
An Approach to Develop Hansel-Spittel Constitutive Equation during Ingot Breakdown Operation of Low Alloy Steels
}

\begin{abstract}
The control of the final quality of a forged product requires an in-depth comprehension of quality of the initial cast ingot. Hot workability is an important property which can be evaluated by variation of strain, strain rate, and temperature. Modeling of forging process always needs to define constitutive models for the material involved. In this study, 42CrMo steel with dendritic microstructure was used to generate the flow stress curves. In order to provide accurate predictions of the thermal and mechanical parameters in the actual ingot break down operation, hot compression tests were carried out at uniform temperatures ranging from $1050^{\circ} \mathrm{C}$ to $1200^{\circ} \mathrm{C}$ and strain rates from $0.25 \mathrm{~s}^{-1}$ to $2 \mathrm{~s}^{-1}$. Finally, Hansel-Spittel law was developed to represent the dependency of the material flow stress on strain, strain rate and temperature. FE Simulation results reveal that the model is able to predict the adiabatic heating during deformation.
\end{abstract}

\section{Introduction}

Hot workability is an important property to estimate materials plastic deformation ability, which is usually defined as the amount of deformation that a material can undergo without cracking and reach desirable mechanical properties and microstructure at a given temperature and strain rate is generally evaluated by various parameters like strain rate, strain and temperature. Forging of ingot after casting starts with ingot breakdown process which is generally performed at very high temperatures ( 0.75 of melting point " $\left.\boldsymbol{M}_{\boldsymbol{P}}{ }^{\prime \prime}\right)$ so as to breakdown the chemical (macrosegregation) and microstructural structure (as-cast dendritic) inhomogeneity [1]. Flow characteristic of a hot forging process consists of strain hardening and softening due to dynamic processes like recrystallization and recovery, which basically determines the quality of a forging product. Constitutive relations are often used to model the forging process in order to describe the plastic flow properties of metals and alloys, many research groups have attempted to develop constitutive equations using various models to describe the flow behavior of various alloys using experimental data [2-5]. Despite large efforts 
being made on the development of constitutive equations for $42 \mathrm{CrMo}$, further investigation has to be done describing the behaviour of $42 \mathrm{CrMo}$ in its as-cast structure at very high temperatures $(\sim 0.7 \mathrm{Mp})$ so as to describe the flow behavior during the ingot breakdown process. Therefore the objective of this study is to investigate the nature of the influence of strain rate and temperature on compressive deformation characteristics of $42 \mathrm{CrMo}$ using hot compressive tests. A model describing the relationship of flow stress, strain rate, strain and temperature is proposed and used to simulate real time analysis of the process using Forge NxT $1.0^{\circledR}$ software.

\section{Experimental}

As- cast $42 \mathrm{CrMo}$ high strength steel was used for the present investigation. The composition of the alloy is shown in Table1. The materials were provided by Finkl Steel Co., Sorel Tracy, Quebec, Canada. Cylindrical specimens were machined with a diameter of $10 \mathrm{~mm}$ and a height of $15 \mathrm{~mm}$. Hot compression tests were performed in Gleeble 3800 Thermomechanical Simulator at four different temperatures $\left(1050,1100,1150\right.$ and $\left.1200^{\circ} \mathrm{C}\right)$ and four strain rates $\left(0.25,0.5,1\right.$ and $\left.2 \mathrm{~s}^{-1}\right)$. The heating rate was $2^{\circ} \mathrm{C} / \mathrm{Sec}$ till $1260^{\circ} \mathrm{C}$ where it was maintained for $300 \mathrm{sec}$ so as to get homogenous temperature over the specimen. The specimen was then cooled to a respective deformation temperature at a cooling rate of $1{ }^{\circ} \mathrm{C} / \mathrm{Sec}$.

Table 1: Composition of as-cast 42CrMo (Wt.\%)

\begin{tabular}{ccccccc}
\hline $\mathrm{C}$ & $\mathrm{Mn}$ & $\mathrm{Si}$ & $\mathrm{Mo}$ & $\mathrm{Cr}$ & $\mathrm{Ni}$ & Other \\
\hline 0.35 & 0.85 & 0.40 & 0.45 & 1.85 & Added & Microalloying \\
\hline
\end{tabular}

\section{Results}

For the present report, results from a deformation temperature of $1200^{\circ} \mathrm{C}$ and $1150{ }^{\circ} \mathrm{C}$ at strain rates of $0.25 \mathrm{~s}^{-1}$ and $2 \mathrm{~s}^{-1}$ are considered. Stress- strain curve of hot compression tests (Fig. 1) reveals that at low strain rates, dynamic softening mechanisms get activated and results in stress drop after a peak stress. This is a typical recrystallization curve, which comprises of four states: the work hardening state, transition state, softening state and steady state. At high strain rates, the flow curves rises sharply and then attains a steady state. This type of flow curve resembles to that of recovery behavior due to which the flow stress attains a steady state due to dislocation generation and annihilation process running simultaneously. Dislocations are particularly needed to build a reservoir of stored energy. This stored energy along with the thermal energy is useful breaking down the coarse grains and generating much finer recrystallized grains. High temperatures can provide sufficient driving force along with dissolution of precipitates can lead to dislocation annihilation and thus softening can be seen as in Fig. 1 at strain rate of $0.25 \mathrm{~s}^{-1}$. However, higher strain rates do not show softening even at 
high temperatures due to the fact that critical driving force has not reached because of high Zener Hollomon factor, Z [6]. Low strain rates promote sufficient driving force for the dislocation annihilation and thus softening can be seen in Fig 1(a).

\section{Constitutive Equation of the flow stress}

To investigate the deformation behavior of as-cast $42 \mathrm{CrMo}$ steel, there is a need to develop constitutive equations in order to simulate the process of the ingot breakdown process. Material constants of the constitutive equation can be derived from the stress strain data obtained from the hot compression tests. To simulate bulk metal forming, Forge NxT $1.0^{\circledR}$ software is used which generally uses thermo- viscoplastic constitutive models under hot conditions. One of the most used models for bulk forming is Hansel-Spittel model. It is based on simple relation on three variables like strain, strain rate and temperature. It has been used for various alloys like AZ31 magnesium alloy [7] , 20MoCrS4 [8], Al-0.7\%Mg-0.4\% $\%$ aluminum alloy [9], AA6082 alloy [10]. The model was developed by Hansel and Spittel, commonly termed as HS equation [11] is given as:

$$
\sigma=A e^{m_{1} T} \varepsilon^{m_{2}} \dot{\varepsilon}^{m_{3}} e^{\frac{m_{4}}{\varepsilon}}(1+\varepsilon)^{m_{5} T} e^{m_{7} \varepsilon} \dot{\varepsilon}^{T m_{8}} T^{m_{9}}
$$

where, $\sigma=$ Stress, $\varepsilon=$ Strain, $\dot{\varepsilon}=$ Strain Rate, $T=$ Deformation Temperature, $m_{l}$ to $m_{9}$ define the material's sensitivity to temperature, $m_{5}$ defines coupling temperature and strain, $m_{8}$ term coupling temperature and strain rate, $m_{2}, m_{4}$ and $m_{7}$ define the material's sensitivity to strain and $m_{3}$ depends on the material's sensitivity to strain rate. Usually constants $m_{8}$ and $m_{9}$ are taken as zero. The material constants were calculated using linear regression methods by Origin ${ }^{\circledR}$ software and are provided in Table 2. The constants were then applied in the equation for various values of strain, strain rate and temperature in order to find the values of stress. Fig. 1 shows the comparison between experiment and calculated flow stress curves developed by constitutive equations. The Hensel- Spittel model is able to describe the steady state phase of hot flow stress curves at high strain rate, whereas it was not able to take into account the softening behavior seen at lower strain rates with the difference of maximum $\sim 14 \%$ between calculated and experimental flow stress. It can be observed that the model can fairly predict the peak stress at both the strain rates. The difference in the calculated peak stress and experimental peak stress is maximum $\sim 7 \%$ at both higher and lower strain rates.

Table 2: Parameters of the Hansel-Spittel equation

\begin{tabular}{ccccccc}
\hline$A$ & $m 1$ & $m 2$ & $m 3$ & $m 4$ & $m 5$ & $m 6$ \\
\hline 2136.313 & -0.00243 & 0.2315 & 0.1215 & 0.0001 & -0.001 & 0.3235 \\
\hline
\end{tabular}




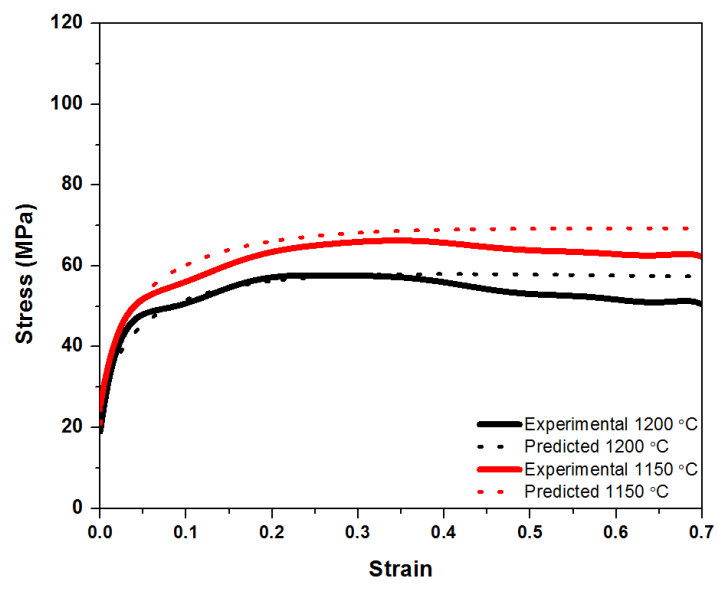

(a)

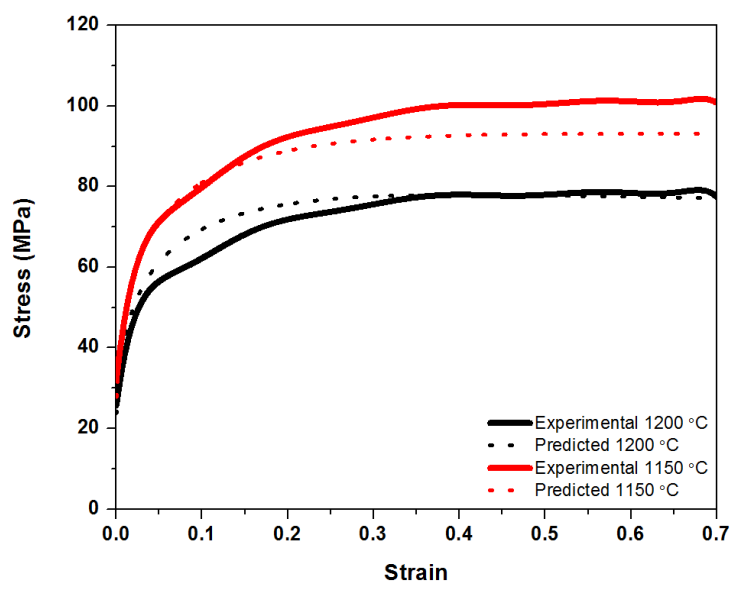

(b)

Fig. 1: Flow curves of $42 \mathrm{CrMo}$ at strain rate of (a) $0.25 \mathrm{~s}^{-1}$ and (b) $2 \mathrm{~s}^{-1}$.

\section{Numerical simulation of 42CrMo hot forging}

Numerical simulations generally consist of various elements which presents the real process. Among the various elements includes the geometrical models of ingot, dies, material model and a set of boundary and initial conditions. The die temperature was kept similar to the deformation temperature. The density of the alloy is $7386.80465 \mathrm{Kg} / \mathrm{m}^{3}$ and specific heat is $661.94 \mathrm{~J} / \mathrm{Kg} /{ }^{\circ} \mathrm{K}$. Hansel spittel model was introduced in Forge NxT $1.0^{\circledR}$ software and two simulations at different strain rates, $0.25 \mathrm{~s}^{-1}$ and $2 \mathrm{~s}^{-1}$ at constant deformation temperature of $1200^{\circ} \mathrm{C}$ were conducted. The temperature distribution map for final stage of deformation for strain rate of $0.25 \mathrm{~s}^{-1}$ and $2 \mathrm{~s}^{-1}$ with deformation temperature $1200^{\circ} \mathrm{C}$ is shown in Fig 2 . It is apparent from the Fig. 2 that temperature distribution in case of higher strain rate is more homogenous than at lower strain rate. Deformation heating is usually generated in any alloy during deformation and is the function of strain rate [1]. This heat generated is usually termed at adiabatic heating and causes higher heat in the sample thereby reducing the flow stress. Adiabatic heating is represented by the following equation:

$$
\Delta T_{\text {Adiabatic }}=\frac{0.95 \int \sigma d \epsilon}{\rho C_{p}}
$$

Where $\Delta T$ is the change in temperature, $\int \sigma d \varepsilon$ is the area under the uncorrected stress- strain curve, $\rho$ is the density, $C_{p}$ the specific heat and 0.95 is the fraction of mechanical work transformed to heat with remaining fraction going to microstructural changes. Adiabatic heat calculated from the experimental data reveals that the temperature at the center at strain rate of $0.25 \mathrm{~s}^{-1}$ and deformation temperature of $1200^{\circ} \mathrm{C}$ is $7.19^{\circ} \mathrm{C}$ at $0.25 \mathrm{~s}^{-1}$ and $14.5^{\circ} \mathrm{C}$ at $2 \mathrm{~s}^{-1}$. From the simulation results, the adiabatic heat generated due to hot compression at strain rate of $0.25 \mathrm{~s}^{-1}$ and $2 \mathrm{~s}^{-1}$ at a deformation temperature of $1200^{\circ} \mathrm{C}$ is $\sim 7^{\circ} \mathrm{C}$ and $\sim 15^{\circ} \mathrm{C}$. It is 
also observed that temperature distribution along the sample after strain of 1 is not uniform at $0.25 \mathrm{~s}^{-1}$ whereas it is significantly uniform at high strain $\left(2 \mathrm{~s}^{-1}\right)$. This temperature distribution reveals that Hansel-Spittel equation significantly predicts the adiabatic heat generated during the deformation at low and high strain rates in case of as-cast $42 \mathrm{CrMo}$ alloy.

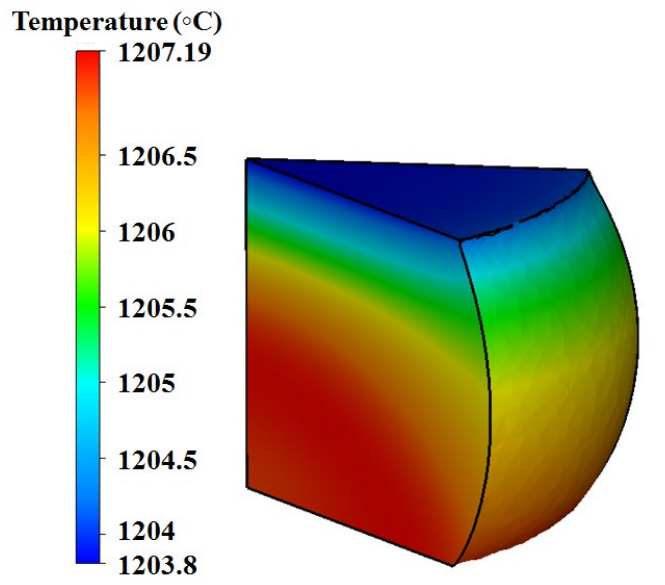

(a)

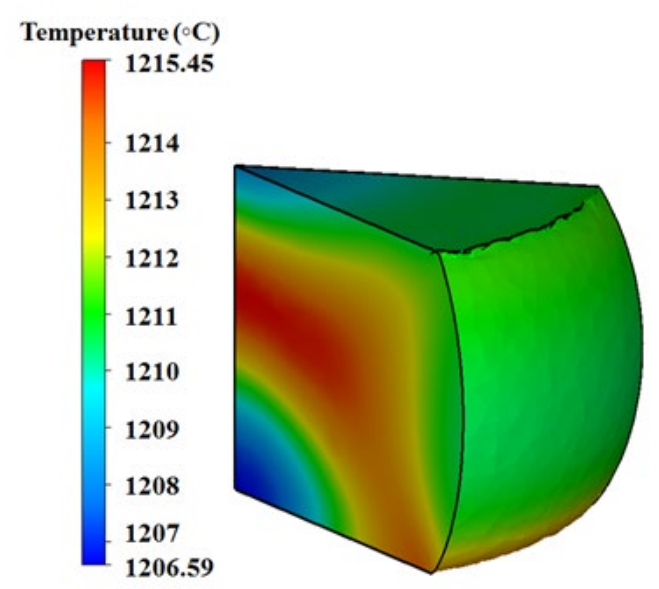

(b)

Fig. 2: Simulated temperature distribution map of $42 \mathrm{CrMo}$ at strain rate of (a) $0.25 \mathrm{~s}^{-1}$ and (b) $2 \mathrm{~s}^{-1}$ at deformation temperature of $1200^{\circ} \mathrm{C}$.

To verify the accuracy this model further, force versus time analysis was compared. Fig. 3 shows the force versus time plot of predicted and experimental data. From the plots, it was found that at lower strain rates, Fig. 3 (a), the difference in predicted and experimental values is $17 \%$, whereas at higher strain rate, Fig. 3 (b), the difference shoots up to $37 \%$. The indifference in the force reading between the experimental and predicted result is mainly due to the effect of friction during hot compression. It is well known fact that friction plays a major role in stress strain plots during hot compression [12]. From the experimental values it was calculated that the friction effect was more at higher strain rates as compared to lower strain rates, which may have been the major cause of this deviation.

\section{Conclusions:}

1. Hot compression of as-cast $42 \mathrm{CrMo}$ alloy reveals that at low strain rates, dynamic recrystallization occurs whereas at low strain rates recovery occurs.

2. Hansel-Spittel equation fairly predicts the flow curves up to peak stress. However it is not able to predict softening of flow stress due to dynamic recrystallization.

3. Simulation results reveal that the model is able to predict the adiabatic heating during deformation, where as it is not able to predict the force with the time. 


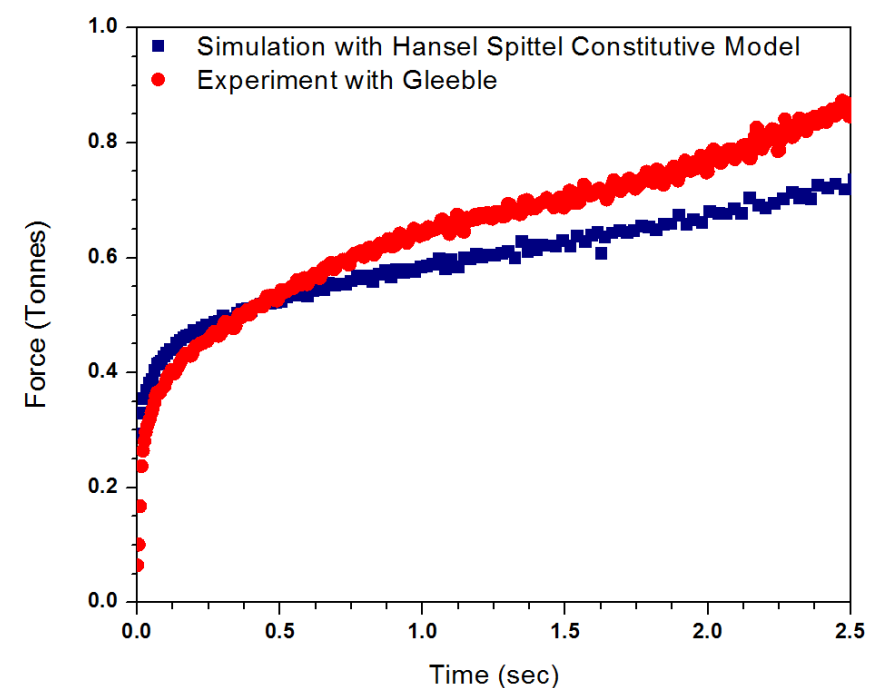

(a)

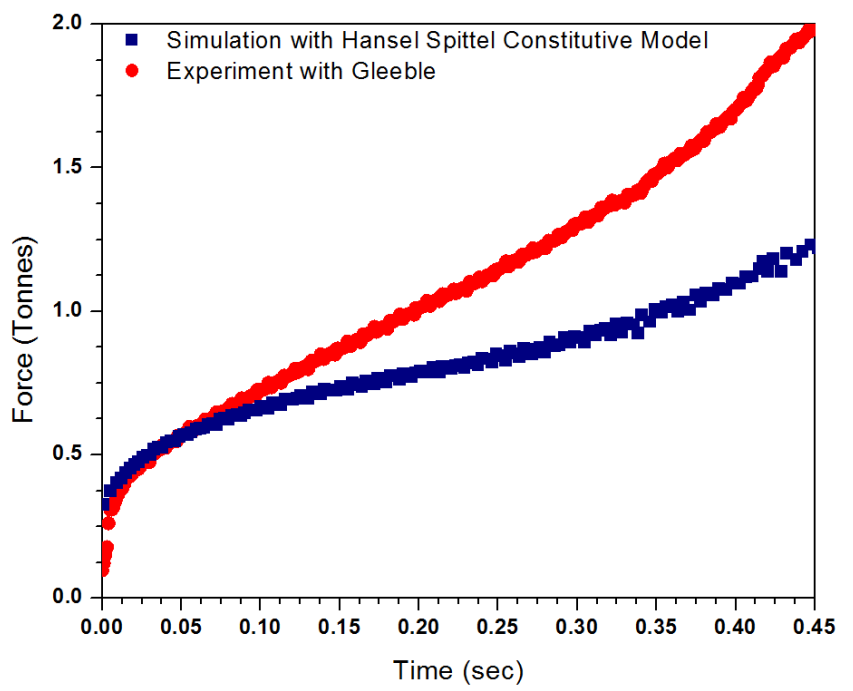

(b)

Fig. 3: Force versus time plot of experimental and predicted at strain rate (a) $0.25 \mathrm{~s}^{-1}$ and (b) $2 \mathrm{~s}^{-1}$ at deformation temperature of $1200^{\circ} \mathrm{C}$.

\section{Acknowledgements}

The authors are very much grateful to Mr. R. Beauvais and Mr. R. Tremblay of Finkel

Steel Co. for providing and machining the specimens for the present research. The authors are also grateful to NSERC for their financial support for this work.

\section{References:}

1. Dieter, G.E., H.A. Kuhn, and S.L. Semiatin, Handbook of Workability and Process Design. 2003: Asm International.

2. Lin, Y.C., M.-S. Chen, and J. Zhong, Constitutive modeling for elevated temperature flow behavior of 42CrMo steel. Computational Materials Science, 2008. 42(3): p. 470-477.

3. Lin, Y.C., M.-S. Chen, and J. Zhong, Effect of temperature and strain rate on the compressive deformation behavior of 42CrMo steel. Journal of Materials Processing Technology, 2008. 205(1-3): p. 308-315.

4. $\quad$ Lin, Y.C., et al., New constitutive model for high-temperature deformation behavior of inconel 718 superalloy. Materials \& Design, 2015. 74(0): p. 108-118.

5. Rao, K.P. and E.B. Hawbolt, Development of Constitutive Relationships Using Compression Testing of a Medium Carbon Steel. Journal of Engineering Materials and Technology, 1992. 114(1): p. 116-123.

6. McQueen, H.J. and J.J. Jonas, Recovery and Recrystallization during High Temperature Deformation, in Treatise on Materials Science \& Technology, A. R.J, Editor. 1975, Elsevier. p. 393-493.

7. Cyganek, Z. and M. Tkocz, The effect of AZ31 alloy flow stress description on the accuracy of forward extrusion FE simulation results. Archives of Metallurgy and Materials, 2012. 57(1): p. 199-204.

8. Meyer, L.W., A. Weise, and F. Hahn. Comparison of constitutive flow curve relations in cold and hot forming. in 5th International Conference on Mechanical and Physical Behaviour of Materials Under Dynamic Loading, 22-26 Sept. 1997. 1997. France: Editions de Physique.

9. El Mehtedi, M., F. Musharavati, and S. Spigarelli, Modelling of the flow behaviour of wrought aluminium alloys at elevated temperatures by a new constitutive equation. Materials \& Design, 2014. 54(0): p. 869873.

10. Donati, L., et al., Grain evolution analysis and experimental validation in the extrusion of 6XXX alloys by use of a lagrangian FE code. International Journal of Plasticity, 2013. 46(0): p. 70-81.

11. Hansel A, S.T., Kraft- und Arbeitsbedarf bildsamer Formgeburgsverfahren.Leipzig, in VEB DeutscherVerlag fur Grundstoffindustrie. 1978.

12. Yunping, L., E. Onodera, and A. Chiba, Friction Coefficient in Hot Compression of Cylindrical Sample. Materials Transactions, 2010. 51(7): p. 1210-15. 